\title{
The effect of feeding rosemary, oregano, saffron and $\alpha$-tocopheryl acetate on hen performance and oxidative stability of eggs
}

\author{
N. Botsoglou ${ }^{1 \#}$, P. Florou-Paneri ${ }^{1}$, E. Botsoglou ${ }^{2}$, V. Dotas ${ }^{2}$, \\ I. Giannenas ${ }^{1}$, A. Koidis ${ }^{1}$ and P. Mitrakos ${ }^{2}$ \\ ${ }^{1}$ Laboratory of Animal Nutrition, School of Veterinary Medicine, Aristotle University, 54006 Thessaloniki, Greece \\ ${ }^{2}$ Laboratory of Animal Nutrition, School of Agriculture, Aristotle University, 54006 Thessaloniki, Greece
}

\begin{abstract}
In this study the effects of feeding rosemary, oregano, saffron and $\alpha$-tocopheryl acetate on hen performance and egg quality were investigated. One hundred-twenty Lohmann laying hens, 32 weeks old, were divided into five groups replicated four times with six hens per replicate. One group was given a basal diet and served as control (CON). The experimental diets given to the other four groups were based on the basal diet but contained an additional $200 \mathrm{mg} \alpha$-tocopheryl acetate $/ \mathrm{kg}$ (TOC), or rosemary at $5 \mathrm{~g} / \mathrm{kg}$ diet (ROS), oregano at $5 \mathrm{~g} / \mathrm{kg}$ diet (ORE) or saffron at $20 \mathrm{mg} / \mathrm{kg}$ diet (SAF). At the end of the feeding trial that lasted 56 days, hen performance and some egg quality characteristics were determined, whereas the oxidative stability of the refrigerated stored shell eggs and liquid yolks were also examined. Results showed no significant differences in egg production, feed intake, feed conversion ratio, egg weight and shape, yolk shape, Haugh units and shell thickness among treatments. However, yolk colour was significantly improved in the SAF group compared to all other groups. The extent of lipid oxidation in shell eggs differed among the dietary treatments, but did not change with storage time. In liquid yolk at $\mathrm{pH} 6.2$, lipid oxidation was higher in the CON group compared to all other groups. The ORE group presented lower oxidation rate than the ROS group, but higher than the SAF group, which in turn exhibited higher oxidation rate than the TOC group. When liquid yolk was acidified to $\mathrm{pH} 4.2$, the lipid oxidation profile remained unchanged but the rate was much more intense.
\end{abstract}

Keywords: Rosemary, oregano, saffron, $\alpha$-tocopherol acetate, egg quality, hen performance, oxidative stability

\# Corresponding author. E-mail: bots@vet.auth.gr

\section{Introduction}

The routine use of in-feed antibiotics to promote growth has been questioned due to the potential development of resistance to a number of pathogenic bacterial species (Wegener et al., 1998). Due to fears of transmission of this resistance to humans through the food chain, all antibacterial feed additives will be banned in the European Union in the near future (European Commission Regulations, 1998). As a consequence, feed additives of plant origin such as essential oils or extracts of aromatic plants that would satisfy consumer perceptions and would be closer to environmentally friendly farming practices, have received considerable attention as alternatives to traditional antibiotic growth promotants. Several studies have been conducted on the effect of dietary essential oils or combinations on the performance of poultry but with varying and often conflicting results. While some reports suggested that dietary herbal essential oils improved growth performance (Alcicek et al., 2003; Basmacioglou et al., 2004), others showed no such effect (Botsoglou et al., 2002a; Lee et al., 2003; Papageorgiou et al., 2003).

Dietary essential oils have also been studied for their antioxidative properties in poultry meat. Supplementation of poultry diets with essential oils has been found to be a simple and convenient strategy to introduce natural antioxidants into meat (Botsoglou et al., 2002a). In vivo studies have shown that oleoresins of rosemary and sage (Lopez-Bote et al., 1998), tea extracts (Tang et al., 2000; 2001) and essential oil of oregano (Botsoglou et al., 2002b; 2003a,b,c; Papageorgiou et al., 2003) could increase the oxidative stability of chicken and turkey tissues when incorporated into their diets.

The oxidative stability of shell eggs has not been an area of major research since their built-in antioxidant characteristics maintain the flavour during extended storage. However, processed eggs are readily subjected to lipid oxidation, particularly at low $\mathrm{pH}$ values (Pike \& Peng, 1988). The susceptibility of 
these eggs to lipid oxidation is of further concern as novel feeding strategies have been adopted to increase the polyunsaturated fatty acid content of eggs (Botsoglou et al., 1998). By increasing the degree of yolk unsaturation the potency to lipid oxidation increases, leading to losses in quality characteristics, nutritional value and consumer acceptability (Cherian et al., 1996).

Research in the use of $\alpha$-tocopherol, an efficient free radical scavenger, in hen feeding has shown that this vitamin is an efficient means for improving the oxidative stability of eggs (Wahle et al., 1993; Cherian et al., 1996; Qi \& Sim, 1998), although pro-oxidant effects have also been reported at high supplementation levels (Chen et al., 1998; Gebert et al., 1998). Pertinent research in the use of aromatic plants in hen feeding is very limited. Botsoglou et al. (1997) reported that dietary supplemented thyme plants delayed lipid oxidation of eggs, whereas Galobart et al. (2001) found that dietary supplementation of a rosemary extract could increase the oxidative stability of hen eggs at high supplementation levels.

In a recent study assessing the antioxidant properties of some spices that are frequently used in the Mediterranean diet, rosemary, oregano and saffron were reported to be effective scavengers of peroxyl radicals in an ox brain phospholipid system compared with other common food additives (Martinez-Tomme et al., 2001). Saffron, the dried red stigmas of Crocus sativus L., is an aromatic spice widely used in the food industry for its colouring properties. It has been also used as an analgesic in traditional medicinal preparations and has recently been shown to have distinct antioxidant properties (Rios et al., 1996). The main biologically active constituents of saffron are crocins, a family of red-coloured and water-soluble carotenoids, which are all glycosides of crocetin (Tarantilis et al., 1995; Tarantilis \& Polissiou, 1997). Both crocins and crocetins exhibit substantial antioxidative activity, however, their antioxidative mechanism has not yet been adequately elucidated (Rios et al., 1996; Pham et al., 2000).

Oregano, a spice obtained by drying leaves and flowers of Origanum vulgare subsp. hirtum plants, is also well known for its antimicrobial and antioxidant properties (Sivropoulou et al., 1996). Major components principally responsible for these properties are carvacrol and thymol, whereas other minor constituents are $\gamma$-terpinene and $p$-cymene (Adam et al., 1998; Yanishlieva et al., 1999).

Rosemary, a spice obtained by drying leaves of Rosmarinus officinalis plants, contains a wide range of different phenolic compounds with varying antioxidative activity. Carnosic acid is the major phenolic constituent present in rosemary leaves with an antioxidant activity approximately three times higher than carnosol and seven times higher than the synthetic antioxidants butylated hydroxytoluene and butylated hydroxyanisole (Richheimer et al., 1996). Rosemary also contains lesser amounts of other antioxidants including carnosol, rosmanol, epirosmanol, rosmarinic acid, and their methoxy-derivatives (Cuvelier et al., 1996)

The objective of the present study was to evaluate the effect of feeding rosemary, oregano, saffron and $\alpha$-tocopheryl acetate on hen performance, some egg quality characteristics and oxidative stability of eggs.

\section{Materials and Methods}

One hundred and twenty Lohmann laying hens, 32 weeks old, purchased from a local poultry farm, were assigned on the basis of their weight into five equal groups replicated four times with six hens per replicate. Hens within the control group $(\mathrm{CON})$ were given a commercial basal diet supplemented with 30 $\mathrm{mg} \alpha$-tocopheryl acetate $/ \mathrm{kg}$, derived from a premix. The $\alpha$-tocopheryl acetate preparation used in the basal diet was obtained from BASF (Germany). The ingredients and the nutrient composition of the basal diet are presented in Table 1. The remaining four groups were given the same basal diet further supplemented with an additional $200 \mathrm{mg} \alpha$-tocopheryl acetate $/ \mathrm{kg}$ (TOC), rosemary at $5 \mathrm{~g} / \mathrm{kg}$ diet (ROS), oregano at $5 \mathrm{~g} / \mathrm{kg}$ diet (ORE) or saffron at $20 \mathrm{mg} / \mathrm{kg}$ diet (SAF). Rosemary consisted of flowered tops and leaves of Rosmarinus officinalis, whereas oregano of flowered tops, leaves, stems and stalks of Origanum vulgare subsp. hirtum plants that had been dried and ground to pass a $2 \mathrm{~mm}$ screen. Saffron consisted of the dried red stigmas of Greek saffron (Crocus sativus L.) that were kindly supplied by the Co-operation of Saffron, Krokos, Kozani, Greece.

All diets were in form of mash and stored in airtight containers. During the feeding period that lasted eight weeks, diets and water were provided ad libitum, whereas the lighting regimen was $15 \mathrm{~h}$ of continuous light per day.

All hens were weighed at the start of the experiment and at intervals of two weeks until the end of the experiment. Feed intake, egg production and total egg weight were recorded daily. Egg quality 
characteristics including egg weight, egg shape index, yolk shape index, yolk colour, Haugh units and shell thickness were measured weekly using eight eggs from each dietary treatment. The oxidative stability of eggs was evaluated using 10 eggs from each replicate totalling 40 eggs from each dietary treatment. Egg collection for this purpose commenced six weeks after the start of the feeding trial and lasted two weeks. All eggs collected during that period, were stored at $4{ }^{\circ} \mathrm{C}$, pending further handling.

Table 1 Ingredients and composition of basal diet

\begin{tabular}{lccc}
\hline Ingredients & $\begin{array}{c}\text { Composition } \\
(\mathrm{g} / \mathrm{kg})\end{array}$ & Chemical analysis*** & $\begin{array}{c}\text { Concentration } \\
(\mathrm{g} / \mathrm{kg})\end{array}$ \\
\hline Maize & 640 & Dry matter & 898 \\
Soyabean meal & 125 & Crude protein & 160 \\
Full-fat soyabean meal & 75 & Ether extract & 49 \\
Herring meal & 25 & Crude fibre & 44 \\
Wheat bran & 35 & Ash & 96 \\
DL-Methionine & 1 & Calcium & 32.5 \\
Limestone & 80 & Phosphorus (total) & 6.8 \\
Dicalcium phosphate & 12 & Calculated analysis & 8.3 \\
Sodium chloride & 3 & Lysine & 6.8 \\
Vitamin premix & 2 & Methionine+cystine & 11.5 \\
Trace-mineral premix** & 2 & Metabolizable energy $(\mathrm{MJ} / \mathrm{kg})$ & \\
\end{tabular}

\footnotetext{
* Supplying per kg diet: vitamin $\mathrm{A}$ - $12500 \mathrm{IU}$; vitamin $\mathrm{D}_{3}$ - $1250 \mathrm{IU}$; vitamin $\mathrm{E}$ - $30 \mathrm{mg}$; vitamin $\mathrm{B}_{1}$ - 2 mg; vitamin $B_{2}-4 \mathrm{mg}$; vitamin $\mathrm{B}_{6}-3 \mathrm{mg}$; vitamin $\mathrm{B}_{12}-0.02 \mathrm{mg}$; vitamin $\mathrm{K}_{3}-2 \mathrm{mg}$; nicotinic acid - $20 \mathrm{mg}$; pantothenic acid - $10 \mathrm{mg}$; folic acid $-1 \mathrm{mg}$; biotin $-0.08 \mathrm{mg}$; vitamin C - $50 \mathrm{mg}$; choline - $300 \mathrm{mg}$

**Supplying per kg diet: Zn - 80 mg; Mn - 40 mg; Fe - 160 mg; Cu - 7 mg; Co - 0.2 mg; I - 1 mg; Se - 0.2 mg ***According to AOAC (1990)
}

To investigate the effect of diet on lipid oxidation of shell eggs during refrigerated storage, four eggs from each replicate collected during the last week of the feeding trial, totalling 16 eggs from each dietary treatment were placed in a refrigerated cabinet at $4{ }^{\circ} \mathrm{C}$ to be analyzed for yolk malondialdehyde (MDA) content at $0,15,30,45$ and 60 days of storage. To investigate further the effect of diet on the oxidative stability of liquid yolk, six more eggs from each replicate collected also during the last week of the feeding trial, totalling 24 eggs from each dietary treatment were broken, yolks were separated and adhering albumen was removed by rolling on a paper towel. Yolk pools were prepared from each replicate and the contents were mixed with a wire whisk.

For studying the effect of diet on the oxidative stability of liquid yolk (Botsoglou et al., 1997), two $9 \mathrm{~g}$ portions were taken from each pool and transferred into two $100 \mathrm{~mL}$ flasks where $10 \mathrm{~mL}$ of water were also added. Water addition was indispensable for decreasing yolk viscosity and providing rapid dispersion of other solutions added thereafter. The content of one of the flasks was adjusted to $\mathrm{pH} 4.2$ by addition, under vigorous vortexing, of $2 \mathrm{~N}$ hydrochloric acid, whereas the $\mathrm{pH}$ of the other flask was left at its initial value of 6.2. To prevent microbial growth, a volume of $50 \mu \mathrm{L}$ of sodium azide solution $(60 \mathrm{mg} / \mathrm{mL})$ was also added to each flask. Following $\mathrm{pH}$ adjustment, additional water was pipetted in each flask to adjust the volume of total liquids added to $16 \mathrm{~mL}$. All flasks were then covered with air-permeable film to retain moisture yet not to exclude air, and submitted to medium agitation on a temperature-controlled shaker bath (GFL, Gmbh, Hannover, Germany) at $20^{\circ} \mathrm{C}$ under artificial light. To ensure even exposure of samples to air during the 15 day period of agitation, all flasks were inspected daily for film cracking. During the first day of agitation, and at time intervals of three days thereafter, 2 or $1 \mathrm{~g}$ samples were removed from each flask and directly analyzed for MDA concentration.

Lipid oxidation was assessed on the basis of the MDA formed during refrigerated storage. MDA, the compound used as an index of lipid peroxidation, was determined by a selective third-order derivative spectrophotometric method (Botsoglou et al., 1994). In brief, yolk samples were homogenized (Polytron homogenizer, PCU, Switzerland) in the presence of $8 \mathrm{~mL}$ of $5 \%$ aqueous trichloroacetic acid and $5 \mathrm{~mL}$ of 
$0.8 \%$ butylated hydroxytoluene in hexane, and the mixture was centrifuged. The top layer was discarded, and a $2.5 \mathrm{~mL}$ aliquot from the bottom layer was mixed with $1.5 \mathrm{~mL}$ of $0.8 \%$ aqueous 2-thiobarbituric acid, to be further incubated at $70{ }^{\circ} \mathrm{C}$ for $30 \mathrm{~min}$. Following incubation, the mixture was cooled under tap water and submitted to conventional spectrophotometry (Shimadzu, Model UV-160A, Tokyo, Japan) in the range of $400-650 \mathrm{~nm}$. Third-order derivative spectra were produced by digital differentiation of the normal spectra using a derivative wavelength difference setting of $21 \mathrm{~nm}$. The concentration of MDA in analyzed samples (ng/g yolk) was calculated on the basis of the height of the third-order derivative peak at $521.5 \mathrm{~nm}$ by referring to slope and intercept data of the computed least-squares fit of a standard calibration curve prepared using 1,1,3,3-tetraethoxypropane, the precursor of MDA. Butylated hydroxytoluene, 2-thiobarbituric acid, and 1,1,3,3-tetraethoxypropane were obtained from Sigma Chemical Co. (St. Louis, MO), whereas trichloroacetic acid was obtained from Merck (Darmstadt, Germany).

All data for hen performance and egg quality parameters were subjected to analysis of variance in the general linear model using the SPSS 12.00 statistical package (SPSS Ltd., Woking, Surrey, UK). The Levene's test was applied to test the homogeneity of the variances. The development of MDA in eggs during storage was analyzed by a two-way analysis of variance, fixed effects model, including main effects of dietary treatment (5 levels) and time of storage (4 levels). When significant treatment effects were disclosed at probability level of $\mathrm{P}<0.05$, the Tukey's test was applied to determine statistical differences between means.

\section{Results and Discussion}

The effect of dietary treatments on some hen performance parameters is presented in Table 2. Egg production, feed intake and feed conversion ratio values were not significantly $(P>0.05)$ changed by the dietary treatments.

Table 2 Effect of dietary rosemary (ROS), oregano (ORE), saffron (SAF) and $\alpha$-tocopheryl acetate (TOC) on egg production, daily feed intake and feed conversion ratio

\begin{tabular}{cccc}
\hline Dietary treatments & Egg production (\%) & Daily feed intake $(\mathrm{g} /$ hen) & Feed conversion ratio \\
\hline CON & 89.9 & 103.3 & 1.76 \\
ROS & 87.7 & 106.7 & 1.79 \\
ORE & 91.0 & 101.8 & 1.74 \\
SAF & 88.8 & 106.8 & 1.81 \\
TOC & 90.4 & 104.3 & 1.78 \\
& & & 0.01 \\
SEM & 0.52 & 0.69 & $>0.05$ \\
P value & $>0.05$ & $>0.05$ &
\end{tabular}

CON - basal diet; ROS - diet with $5 \mathrm{~g}$ rosemary $/ \mathrm{kg}$; ORE - diet with $5 \mathrm{~g}$ oregano $/ \mathrm{kg}$; SAF - diet with $20 \mathrm{mg}$ saffron $/ \mathrm{kg}$; TOC - diet with $200 \mathrm{mg} \alpha$-tocopheryl acetate $/ \mathrm{kg}$

These results cannot be compared with literature data since there are no reports on the use of these aromatic plants in hen feeding. However, pertinent studies with $\alpha$-tocopheryl acetate have shown no significant differences in egg production and feed intake when laying hens were given a diet supplemented with up to $200 \mathrm{mg} \alpha$-tocopheryl acetate/kg (Jiang et al., 1994; Qi \& Sim, 1998). Jiang et al. (1994), in particular, reported a decreased feed intake when hens were fed $400 \mathrm{mg} \alpha$-tocopheryl acetate $/ \mathrm{kg}$, whereas Qi $\&$ Sim (1998) did not observe such an effect even when the hens were given a diet supplemented with up to $800 \mathrm{mg} \alpha$-tocopheryl acetate $/ \mathrm{kg}$.

Apart from the diet, the observed lack of performance-promoting effects might relate to the environmental conditions. Well-nourished healthy hens may not respond to a performance-promoting supplement when they are housed under clean, disinfected conditions and moderate stocking density. Consequently, little or no response could be expected with high environmental standards, but with lower standards the response to the dietary treatments might increase. 
Table 3 Effect of dietary rosemary (ROS), oregano (ORE), saffron (SAF) and $\alpha$-tocopheryl acetate (TOC) on some egg quality characteristics

\begin{tabular}{ccccccc}
\hline $\begin{array}{c}\text { Dietary } \\
\text { treatments }\end{array}$ & $\begin{array}{c}\text { Egg } \\
\text { weight }(\mathrm{g})\end{array}$ & $\begin{array}{c}\text { Egg } \\
\text { shape index }\end{array}$ & $\begin{array}{c}\text { Yolk } \\
\text { shape index }\end{array}$ & $\begin{array}{c}\text { Yolk } \\
\text { colour }\end{array}$ & $\begin{array}{c}\text { Haugh } \\
\text { units }\end{array}$ & $\begin{array}{c}\text { Shell } \\
\text { thickness (mm) }\end{array}$ \\
\hline CON & 66.3 & 77.4 & 0.47 & $10.0^{\mathrm{a}}$ & 87.8 & 0.36 \\
ROS & 66.4 & 77.2 & 0.46 & $10.1^{\mathrm{a}}$ & 85.4 & 0.37 \\
ORE & 65.2 & 77.2 & 0.46 & $10.0^{\mathrm{a}}$ & 85.7 & 0.37 \\
SAF & 66.7 & 77.7 & 0.46 & $11.0^{\mathrm{b}}$ & 86.6 & 0.36 \\
TOC & 65.6 & 77.0 & 0.47 & $10.2^{\mathrm{a}}$ & 87.4 & 0.36 \\
SEM & 0.20 & 0.17 & 0.16 & 0.16 & 3.4 & 0.18 \\
P value & $>0.05$ & $>0.05$ & $>0.05$ & $<0.05$ & $>0.05$ & $>0.05$ \\
\hline
\end{tabular}

CON - basal diet; ROS - diet with $5 \mathrm{~g}$ rosemary $/ \mathrm{kg}$; ORE - diet with $5 \mathrm{~g}$ oregano $/ \mathrm{kg}$; SAF - diet with $10 \mathrm{mg}$ saffron $/ \mathrm{kg}$; TOC - diet with $200 \mathrm{mg} \alpha$-tocopheryl acetate $/ \mathrm{kg}$

${ }^{\mathrm{a}, \mathrm{b}}$ values within column with common superscript do not differ $(\mathrm{P}>0.05)$

The effect of dietary treatments on some egg quality characteristics is shown in Table 3 . There were no significant $(\mathrm{P}>0.05)$ differences in egg weight and shape, yolk shape, Haugh units and shell thickness among treatments. Jiang et al. (1994) and Qi \& Sim (1998) also reported no significant effect on egg weight, yolk weight and Haugh units when $\alpha$-tocopheryl acetate was supplemented in hen diets at the level of 200 $\mathrm{mg} / \mathrm{kg}$. Pertinent reports on the use of these aromatic plants in hen feeding have not yet been presented in literature.

Yolk colour was significantly improved in the SAF group compared to all other groups (Table 3). This improvement in yolk colour indicated a passage of crocins, lycopene and carotene, the colouring components of saffron, from hen diet into egg yolk (Tarantilis et al., 1995).

The effect of dietary treatments on lipid oxidation of shell eggs refrigerated for 60 days is shown in Figure 1. The extent of lipid oxidation, as measured by MDA formation, differed $(\mathrm{P}<0.05)$ among the dietary treatments but did not change $(\mathrm{P}>0.05)$ with storage time. The TOC group exhibited higher $(\mathrm{P}<$ $0.05)$ oxidative stability than all other groups. The SAF group presented better $(\mathrm{P}<0.05)$ oxidative stability than the ROS and ORE groups, which did not differ $(\mathrm{P}>0.05)$ from each other. The CON group presented lower $(\mathrm{P}<0.05)$ oxidative stability than all other groups.

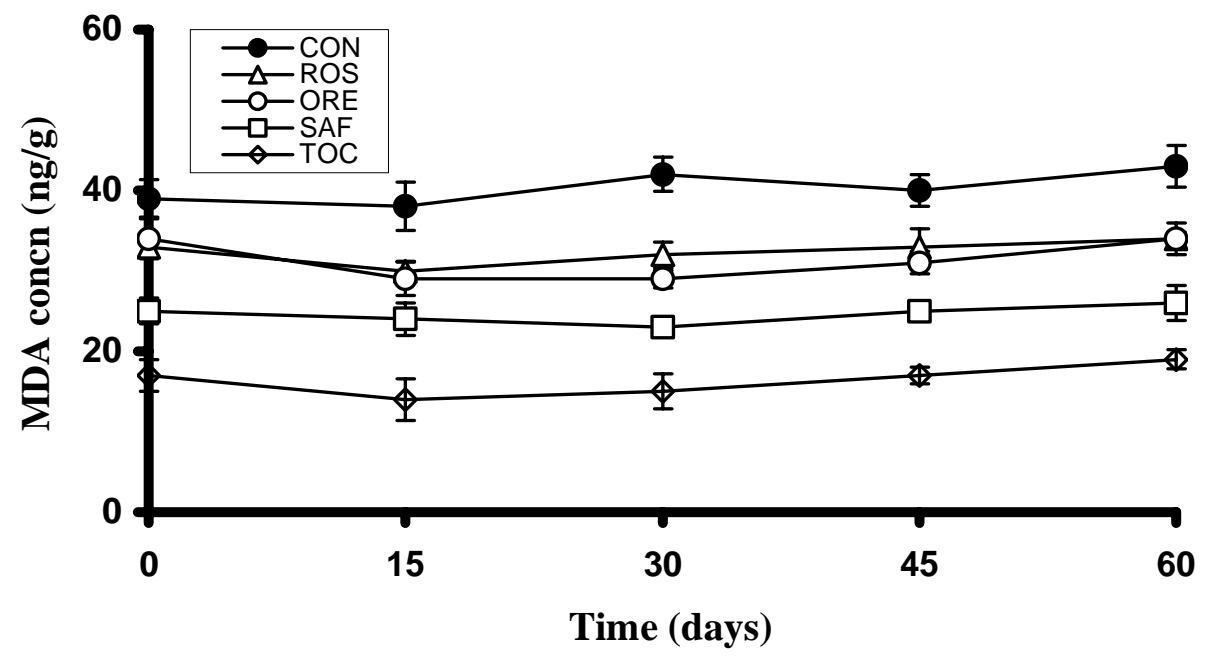

Figure 1 Effect of refrigerated storage on lipid oxidation of yolks of shell eggs as a function of supplementation of hen diets with rosemary (ROS), oregano (ORE), saffron (SAF) or $\alpha$-tocopheryl acetate (TOC) at the levels of $5 \mathrm{~g} / \mathrm{kg}, 5 \mathrm{~g} / \mathrm{kg}, 20 \mathrm{mg} / \mathrm{kg}$ or $200 \mathrm{mg} / \mathrm{kg}$ diet, respectively, compared to the control diet $(\mathrm{CON})$ 
The MDA found in the yolk of shell eggs during storage might be attributed to either the consumption and subsequent deposition of the MDA that was already present in the diets or to its in vivo production by the hens fed the diets. The former possibility appears unlikely because in that case the levels of MDA should have been equal among treatments. However, MDA analysis of diets revealed similar $(\mathrm{P}>0.05)$ values. The latter possibility seems more reasonable because the possible transfer of the antioxidant constituents of the dietary supplements into the hen may result in these constituents being involved in oxidative processes in the hen thus decreasing the quantity of MDA transferred into yolks.

Although the obtained MDA values were very low and confirm the oxidative stability of fresh eggs, as has been previously described by some authors (Marshall et al., 1994; Cherian et al., 1996; Botsoglou et al., 1997), the observed differences in the MDA values demonstrated the antioxidant potential of each of the tested dietary supplements. Direct comparison of the results of this study with other pertinent studies is difficult since in previous reports dealing with the oxidative stability of shell eggs, most evaluated the use of $\alpha$-tocopherol. Marshall et al. (1994) and Cherian et al. (1996) also reported that dietary use of $\alpha$-tocopherol in laying hens increased the oxidative stability of fresh eggs. In the literature, there has been only one report dealing with the dietary use of aromatic plants for increasing the oxidative stability of shell eggs, but it concerns the use of thyme, a spice with chemical composition very close to that of oregano (Botsoglou et al., 1997). In that report, thyme was also found to increase the oxidative stability of shell eggs refrigerated for 60 days.

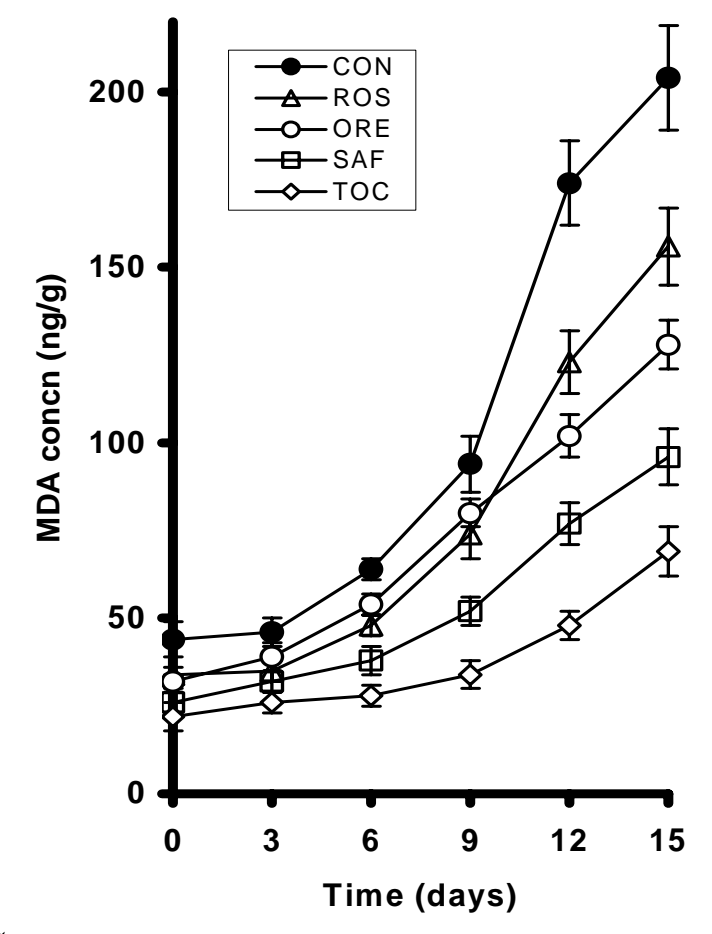

a

Figure 2 Effect of agitation time under artificial light at $20^{\circ} \mathrm{C}$ on lipid oxidation of liquid yolks at pH 6.2 (a) and 4.2 (b) as a function of dietary supplementation of hen diets with rosemary (ROS), oregano (ORE), saffron (SAF) or $\alpha$-tocopheryl acetate (TOC) at the levels of $5 \mathrm{~g} / \mathrm{kg}, 5 \mathrm{~g} / \mathrm{kg}, 20 \mathrm{mg} / \mathrm{kg}$ or $200 \mathrm{mg} / \mathrm{kg}$ diet, respectively, compared to control diet (CON) 
Since shell eggs are inherently resistant to oxidative deterioration upon refrigerated storage, additional experiments were carried out in order to evaluate yolk lipid stability under conditions that could promote lipid oxidation. Figure 2a shows the effect of dietary treatments on the oxidative stability of yolks agitated for 15 days under artificial light at $20^{\circ} \mathrm{C}$. Agitation increased the levels of MDA in all samples, the increase being higher in the CON group and lower in the TOC group. Samples from the other groups fed on diets supplemented with rosemary, oregano and saffron had intermediate MDA values, a finding suggesting that these diets increased the oxidative stability of the egg yolk. At day 3 of agitation, MDA levels did not differ $(\mathrm{P}<0.05)$ among the dietary treatments. At days 6 and 9 , significant differences in the MDA values appeared among the dietary treatments $(\mathrm{P}<0.05)$, although the ROS and ORE group continued to present similar MDA values. However, at days 12 and 15, MDA values of the ROS and ORE groups differed $(\mathrm{P}<$ $0.05)$ from each other. Thus, eggs from the CON group presented higher $(\mathrm{P}<0.05) \mathrm{MDA}$ values than those of all other groups, whereas eggs from the TOC group presented lower $(\mathrm{P}<0.05)$ MDA values than all other groups. The SAF group presented lower $(\mathrm{P}<0.05) \mathrm{MDA}$ values than the ORE group, which in turn was lower $(\mathrm{P}<0.05)$ than the ROS group.

Because the rate of lipid oxidation increases as yolk $\mathrm{pH}$ decreases from its initial value of 6.2 to lower values (Botsoglou et al., 1997), the effect of dietary treatments on the oxidative stability of yolks was further investigated under more favourable conditions for lipid oxidation such as at $\mathrm{pH} 4.2$, a $\mathrm{pH}$ similar to that found in yolk-containing acidic foodstuff preparations like mayonnaise. Figure $2 \mathrm{~b}$ shows the effect of dietary treatments on the oxidative stability of yolks acidified at $\mathrm{pH} \mathrm{4.2.} \mathrm{Upon} \mathrm{acidification,} \mathrm{the} \mathrm{rate} \mathrm{of} \mathrm{lipid}$ oxidation greatly increased compared to yolks at $\mathrm{pH}$ 6.2. Again, at day 3 of agitation, MDA levels did not differ $(\mathrm{P}<0.05)$ among the dietary treatments. However, at day 6 and thereafter 9 , significant differences in the MDA values appeared among the dietary treatments $(\mathrm{P}<0.05)$, although the ROS and ORE group continued to present similar $(\mathrm{P}<0.05) \mathrm{MDA}$ values by day 15 . Thus, eggs from the CON group presented higher $(\mathrm{P}<0.05)$ MDA values than those of all other groups, whereas eggs from the TOC group lower $(\mathrm{P}<$ $0.05)$ MDA values than all other groups. The SAF group presented lower $(\mathrm{P}<0.05)$ MDA values than the ORE and ROS groups.

Consistent with the results of the present study, Botsoglou et al. (1997) observed improvement of the oxidative stability of egg yolk at both normal and acidic $\mathrm{pH}$ values, in eggs from laying hens fed thyme supplemented diets. Krause \& Ternes (2000) also found improvement of the oxidative stability of egg yolk when carnosic acid, the main antioxidant constituent of rosemary, was used as a dietary supplement in laying hens. In contrast, Galobart et al. (2001) reported that the dietary supplementation of a rosemary extract to laying hens had no effect on lipid oxidation of eggs.

\section{Conclusions}

Results showed that there were no significant differences in egg production, feed consumption, feed conversion ratio, egg weight and shape, yolk shape, Haugh units and shell thickness among the dietary treatments. However, yolk colour was improved when saffron was used as a dietary supplement. The lipid oxidation experiments showed that saffron exerted higher antioxidant activity than rosemary and oregano, which presented comparable antioxidant activity, while $\alpha$-tocopherol presented the highest antioxidant activity. Considering that egg yolks from the dietary supplemented groups exhibited increased resistance to lipid oxidation compared to control, one could say that antioxidant constituents of rosemary, oregano and saffron passed from the feed into the developing yolk, providing eggs with increased antioxidant properties.

\section{References}

Adam, K., Sivropoulou, A., Kokkini, S., Lanaras, T. \& Arsenakis, M., 1998. Antifungal activities of Origanum vulgare ssp. hirtum, Mentha spicata, Lavandula angustifolia, and Salvia fruticosa essential oils against human pathogenic fungi. J. Agric. Food Chem. 46, 1739-1745.

Alcicek, A., Bozkurt, M. \& Cabuk, M., 2003. The effect of an essential oil combination derived from selected herbs growing wild in Turkey on broiler performance. S. Afr. J. Anim. Sci. 33, 89-94.

AOAC, 1990. Official methods of analysis $\left(14^{\text {th }}\right.$ ed.). Association of Official Analytical Chemists, Inc., Arlington, Virginia, USA. 
Basmacioglu, H., Tokusoglu, O. \& Ergul, M., 2004. The effect of oregano and rosemary essential oils or $\alpha$ tocopheryl acetate on performance and lipid oxidation of meat enriched with n-3 PUFA's in broilers. S. Afr. J. Anim. Sci. 34, 197-210.

Botsoglou, N.A., Christaki, E., Fletouris, D.J., Florou-Paneri, P. \& Spais, A.B., 2002b. The effect of dietary oregano essential oil on lipid oxidation in raw and cooked chicken during refrigerated storage. Meat Sci. 62, 259-265.

Botsoglou, N.A., Fletouris, D.J., Florou-Paneri, P., Christaki, E. \& Spais, A.B., 2003a. Inhibition of lipid oxidation in long-term frozen stored chicken meat by dietary oregano essential oil and $\alpha$-tocopheryl acetate supplementation. Food Res. Internat. 36, 207-213.

Botsoglou, N.A., Fletouris, D.J., Papageorgiou, G.E., Vassilopoulos, V.N., Mantis, A.J. \& Trakatellis, A.G., 1994. A rapid, sensitive and specific thiobarbituric acid method for measuring lipid peroxidation in animal tissues, food, and feedstuff samples. J. Agric. Food Chem. 42, 1931-1937.

Botsoglou, N.A., Florou-Paneri, P., Christaki, E., Fletouris, D.J. \& Spais, A.B., 2002a. Effect of dietary oregano essential oil on performance of chickens and on iron-induced lipid oxidation of breast, thigh and abdominal fat tissues. Br. Poult. Sci. 43, 223-230.

Botsoglou, N.A., Govaris, A., Botsoglou, E.N., Grigoropoulou, S.H. \& Papageorgiou, G., 2003b. Antioxidant activity of dietary oregano essential oil and $\alpha$-tocopheryl acetate supplementation in longterm frozen stored turkey meat. J. Agric. Food Chem. 51, 2930-2936.

Botsoglou, N.A., Grigoropoulou, S.H., Botsoglou, E., Govaris, A. \& Papageorgiou, G., 2003c. The effects of dietary oregano essential oil and $\alpha$-tocopheryl acetate on lipid oxidation in raw and cooked turkey during refrigerated storage. Meat Sci. 65, 1193-1200.

Botsoglou, N.A., Yannakopoulos, A.L., Fletouris, D.J., Tserveni-Goussi, A.C. \& Fortomaris, P., 1997. Effect of dietary thyme on the oxidative stability of egg yolk. J. Agric. Food Chem. 45, 3711-3716.

Botsoglou, N.A., Yannakopoulos, A.L., Fletouris, D.J., Tserveni-Goussi, A.C. \& Psomas, I., 1998. Yolk fatty acid composition and cholesterol content in response to level and form of dietary flaxseed. J. Agric. Food Chem. 46, 4652-4656.

Chen, J.Y., Latshaw, J.D., Lee, H.O. \& Min, D.B., 1998. $\alpha$-Tocopherol content and oxidative stability of egg yolk as related to dietary $\alpha$-tocopherol. J. Food Sci. 63, 919-922.

Cherian, G., Wolfe, F.W. \& Sim, J.S., 1996. Feeding dietary oils with tocopherols: effects on internal qualities of eggs during storage. J. Food Sci. 61, 15-18.

Cuvelier, M., Richard, H. \& Berset, C., 1996. Antioxidative activity and phenolic composition of pilot-plant and commercial extracts of sage and rosemary. J. Am. Oil Chem. Soc. 73, 645-652.

European Communities, Commission Regulation (EC) No 97/6 of 30 January 1997 amending Council Directive 70/524/EC concerning additives in feeding stuffs, OJ L 96, 28/3/1998:39.

Galobart, J., Barroeta, A., Baucells, M., Codony, R. \& Ternes, W., 2001. Effect of dietary supplementation with rosemary extract and $\alpha$-tocopheryl acetate on lipid oxidation in eggs enriched with $\omega 3$-fatty acids. Poult. Sci. 80, 460-467.

Gebert, S., Messikommer, R., Pfirter, H., Bee, G. \& Wenk, C., 1998. Dietary fats and vitamin E in diets for laying hens: Effects on laying performance, storage stability and fatty acid composition of eggs. Arch. Geflugel. 62, 214-222.

Jiang, Y., McGeachin, R. \& Bailey, C., 1994. $\alpha$-Tocopherol, $\beta$-carotene, and retinal enrichment of chicken eggs. Poult. Sci. 73, 1137-1143.

Krause, E. \& Ternes, W., 2000. Bioavailability of the antioxidative Rosmarinus officinalis compound carnosic acid in eggs. Eur. Food Res. Technol. 3, 161-164.

Lee, K-W., Everts, H., Kappert, H.J., Frehner, M., Losa, R. \& Beynen, A.C., 2003. Effects of dietary essential oil components on growth performance, digestive enzymes and lipid metabolism in female broiler chickens. Br. Poult. Sci. 44, 450-457.

Lopez-Bote, C.J., Gray, J.I., Gomaa, E.A. \& Flegal, C.J., 1998. Effect of dietary administration of oil extracts from rosemary and sage on lipid oxidation in broiler meat. Br. Poult. Sci. 39, 235-240.

Marshall, A.C., Sams, A.R. \& Van Elswyk, M.E., 1994. Oxidative stability and sensory quality of stored eggs from hens fed 1.5\% menhaden oil. J. Food Sci. 59, 561-563. 
Martinez-Tome, M., Jimenez, A., Ruggieri, S., Frega, N., Strabbioli, R. \& Murcia, A., 2001. Antioxidant properties of Mediterranean spices compared with common food additives. J. Food Prot. 64, 14121419.

Papageorgiou, G., Botsoglou, N., Govaris, A., Giannenas, I., Iliadis, S. \& Botsoglou, E., 2003. Effect of dietary oregano oil and $\alpha$-tocopheryl acetate supplementation on iron-induced lipid oxidation of turkey breast, thigh, liver and heart tissues. J. Anim. Physiol. Anim. Nutr. 87, 324-335.

Pham, Q.T., Cormier, F., Farnworth, E., Tong, V.H. \& Van Calsteren, M-R., 2000. Antioxidant properties of Crocin from Gardenia jasminoides Ellis and Study of the reactions of crocin with linoleic acid and crocin with oxygen. J. Agric. Food Chem. 48, 1455-1461.

Pike, O.A. \& Peng, I.C., 1988. Influence of pH on egg yolk lipid oxidation. J. Food Sci. 53, 1245-1246.

Qi, G.H. \& Sim, J.S., 1998. Natural tocopherol enrichment and its effect in n-3 fatty acid modified chicken eggs. J. Agric. Food Chem. 46, 920-1926.

Richheimer, S, Bernart, M., King, G., Kent, C. \& Bailey, D., 1996. Antioxidant activity of lipid-soluble phenolic diterpenes from rosemary. J. Am. Chem. Soc. 73, 507-514.

Rios, J.L., Recio, M.C.R., Giner, M. \& Manez, S., 1996. An update review of saffron and its active constituents. Phytother. Res. 10, 189-193.

Sivropoulou, A., Papanikolaou, E., Nikolaou, C., Kokkini, S., Lanaras, T. \& Arsenakis, M., 1996. Antimicrobial and cytotoxic activities of Origanum essential oils. J. Agric. Food Chem. 44, 12021205.

Tang, S.Z., Kerry, J.P., Sheeham D., Buckley, D.J. \& Morrissey, P.A., 2000. Dietary tea catechins and ironinduced lipid oxidation in chicken meat, liver and heart. Meat Sci. 56, 285-290.

Tang, S.Z., Kerry, J.P., Sheeham D., Buckley, D.J. \& Morrissey, P.A., 2001. Antioxidative effect of dietary tea catechins on lipid oxidation of long-term frozen stored chicken meat. Meat Sci. 57, 331-336.

Tarantilis, P., Tsoupras, G. \& Polissiou, M., 1995. Determination of saffron (Crocus sativus L.) components in crude plant extract using high-performance liquid chromatography UV-visible photodiode-arraydetection mass spectrometry. J. Chromatogr. A 699, 107- 118.

Tarantilis, P.A. \& Polissiou, M.G., 1997. Isolation and identification of the aroma components from saffron. J. Agric. Food Chem. 45, 459-462.

Wahle, K.W.J., Hoppe, P.P. \& McIntosh, G., 1993. Effects of storage and various intrinsic vitamin E concentrations on lipid oxidation in dried egg powders. J. Sci. Food Agric. 61, 463-469.

Wegener, H., Aarestrup, F., Jensen, L., Hammerum, A. \& Bager, F. 1998. The association between the use of antimicrobial growth promoters and development of resistance in pathogenic bacteria towards growth promoting and therapeutic antimicrobials. J. Anim. Feed Sci. Technol. 7, 7-14.

Yanishlieva, V., Marinova, N., Gordon, H. \& Raneva, G., 1999. Antioxidant activity and mechanism of action of thymol and carvacrol in two food lipid systems. Food Chem. 64, 59-66. 